07

\title{
Влияние длины затвора на скорость инжекции электронов в каналах полевых транзисторов на основе AIGaN/AIN/GaN
}

\author{
() С.В. Михайлович, Р.Р. Галиев, А.В. Зуев, А.Ю. Павлов, \\ Д.С. Пономарев, Р.А. Хабибуллин
}

Институт сверхвысокочастотной полупроводниковой электроники РАН, Москва

『 E-mail: e-mail: khabibullin@isvch.ru

Поступило в Редакцию 1 февраля 2017 г.

Исследованы полевые транзисторы с высокой подвижностью электронов (HEMT) на основе $\mathrm{AlGaN} / \mathrm{AlN} / \mathrm{GaN}$ с разной длиной затвора $L_{g}$. Значения максимальных частот усиления по току $f_{T}$ и однонаправленного коэффициента усиления $f_{\max }$ составили 88 и $155 \mathrm{GHz}$ для транзисторов с $L_{g}=125 \mathrm{~nm}$ и 26 и $82 \mathrm{GHz}$ для транзисторов с $L_{g}=360 \mathrm{~nm}$ соответственно. На основе измеренных $S$-параметров проведена экстракция значений элементов малосигнальных эквивалентных схем AlGaN/AlN/GaN HEMT и определена зависимость скорости инжекции $v_{i n j}$ от напряжения затвор-исток. Также исследовано влияние длины затвора и напряжения между стоком и истоком на величину $v_{i n j}$.

DOI: $10.21883 /$ PJTF.2017.16.44927.16727

Широкозонные гетероструктуры на основе нитрида галлия обладают рядом уникальных свойств, в частности высокой плотностью двумерного электронного газа, высоким пробивным напряжением, большой скоростью электронов и т.д. Благодаря этому полупроводниковые СВЧ-приборы на их основе хорошо зарекомендовали себя в низкочастотной области спектра (до $15 \mathrm{GHz}$ ) [1]. Современные технологии для вертикального и горизонтального масштабирования полевых транзисторов с высокой подвижностью электронов (НЕMT) на основе GaN позволили расширить область использования GaN HEMT в миллиметровом диапазоне длин волн (от 30 до $300 \mathrm{GHz}$ ). В частности, было существенно снижено сопротивление омических контактов (до $0.026 \Omega \cdot \mathrm{mm}$ ) путем использования технологии повторного эпитаксиального выращивания высоколегированного 
контактного слоя $n^{+}$-GaN. Была разработана самосовмещенная технология изготовления затвора и омических контактов, способствовавшая уменьшению сопротивления доступа к подзатворной области канала до $0.1 \Omega \cdot \mathrm{mm}$, а также была уменьшена длина затвора до $20 \mathrm{~nm}[2,3]$.

Одной из важных характеристик GaN HEMT, определяющих максимально возможную частоту усиления по току, является скорость электронов в подзатворной области канала [4]. Характерное значение этой скорости для GaN HEMT составляет порядка $10^{7} \mathrm{~cm} / \mathrm{s}$. По сути, это скорость инжекции электронов в подзатворную область НЕМТ из верхней точки потенциального барьера, расположенной на границе затвора со стороны истока („виртуальный исток“), как показано на вставке к рис. 1 .

В настоящей работе исследовано влияние длины затвора $L_{g}$ на скорость инжекции электронов в подзатворную область канала $\mathrm{AlGaN} / \mathrm{AlN} / \mathrm{GaN}$ HEMT миллиметрового диапазона длин волн. Для этого были изготовлены полевые транзисторы на основе гетероструктуры $\mathrm{Al}_{0.3} \mathrm{Ga}_{0.7} \mathrm{~N} / \mathrm{AlN} / \mathrm{GaN}$ с толщиной барьерного слоя $14 \mathrm{~nm}$, подвижностью электронов $2000 \mathrm{~cm}^{2} /(\mathrm{V} \cdot \mathrm{s})$ и концентрацией $1.3 \cdot 10^{13} \mathrm{~cm}^{-2}$, измеренными при температуре $300 \mathrm{~K}$. Сопротивление несплавных омических контактов изготовленных транзисторов составляло $0.18 \Omega \cdot \mathrm{mm}$. Слоевое сопротивление канала составило $300 \Omega / \square$. Технология изготовления транзисторов описана в [5,6]. Исследовалось два типа транзисторов с длиной Т-образных затворов 125 и $360 \mathrm{~nm}$. Ширина затворов в обоих случаях была $2 \times 50 \mu \mathrm{m}$. Для транзисторов с $L_{g}=125 \mathrm{~nm}$ максимальные частоты усиления по току и однонаправленного коэффициента усиления составили $f_{T}=88 \mathrm{GHz}$ и $f_{\max }=155 \mathrm{GHz}$ соответственно. Для транзисторов с $L_{g}=360 \mathrm{~nm}$ значения $f_{T}=26 \mathrm{GHz}$ и $f_{\max }=82 \mathrm{GHz}$. Значение крутизны изготовленных транзисторов составило $410 \mathrm{mS} / \mathrm{mm}$.

Для определения скорости инжекции электронов был использован метод, разработанный для НЕМТ на основе фосфида индия [7]. Экстракция значений элементов малосигнальных эквивалентных схем $\mathrm{AlGaN} / \mathrm{AlN} / \mathrm{GaN}$ HEMT для каждой заданной рабочей точки на основе измеренных $S$-параметров производилась методом, описанным в работах $[8,9]$. Исходя из значений элементов эквивалентных схем определялась полная емкость затвора $\left(C_{g}\right)$, равная сумме емкостей затвор-исток и затвор-сток. По зависимости $C_{g}$ от напряжения между затвором и истоком $\left(V_{g s}\right)$ при неизменном напряжении между стоком и

Письма в ЖТФ, 2017, том 43, вып. 16 


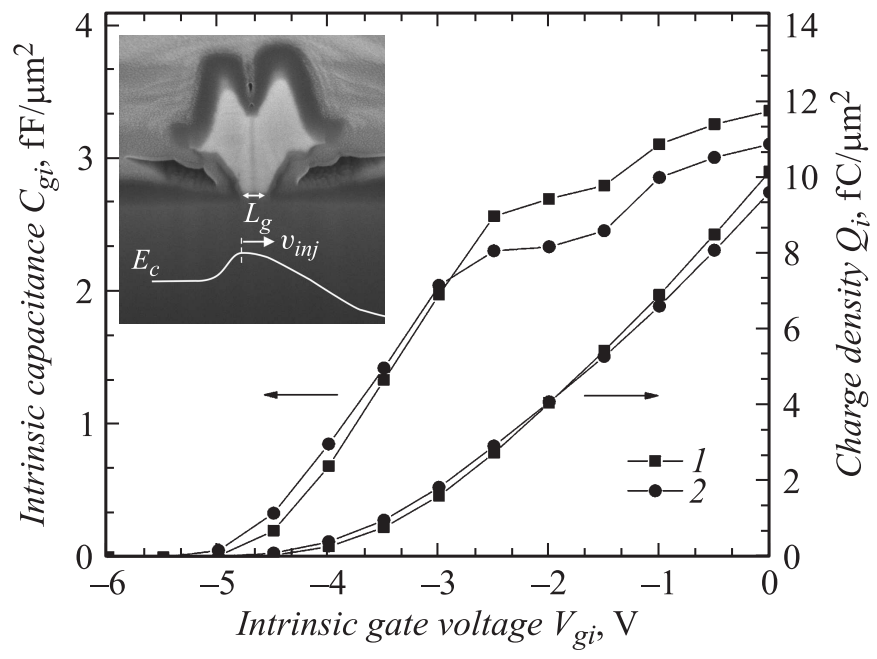

Рис. 1. Зависимость внутренней емкости затвора $C_{g i}$ и плотности заряда в подзатворной области $Q_{i}$ от напряжения $V_{g i}$ между затвором и истоком без учета падения напряжения на омическом контакте со стороны истока для транзисторов с длиной затвора $125 \mathrm{~nm} .1$ - напряжение между стоком и истоком $5 \mathrm{~V}, 2-10 \mathrm{~V}$. На вставке показана фотография Т-образного затвора и схематично изображена скорость инжекции электронов $v_{i n j}$ в точке „виртуального истока“.

истоком определялась паразитная составляющая емкости $C_{g 0}$, которая связана с геометрией затвора и диэлектрической пленкой вокруг него и не зависит от $V_{g s}$. Затем вычислялось внутреннее значение емкости $C_{g i}=C_{g}-C_{g 0}$. Далее, интегрируя удельное (на единицу площади затвоpa) значение емкости $C_{g i}$ по напряжению между затвором и истоком без учета падения напряжения на омическом контакте со стороны истока $\left(V_{g i}=V_{g s}-I_{d} R\right)$, мы получили слоевую плотность заряда в подзатворной области $Q_{i}$, как показано на рис. 1 . На рис. 2 представлена зависимость удельного (на единицу ширины затвора) тока стока $I_{d}$ от $V_{g i}$. Среднее значение скорости инжекции электронов в подзатворную область со стороны истока, согласно [7], равно отношению тока стока к плотности заряда: $v_{i n j}=I_{d} / Q_{i}$. Поделив значения тока стока

Письма в ЖТФ, 2017, том 43, вып. 16 


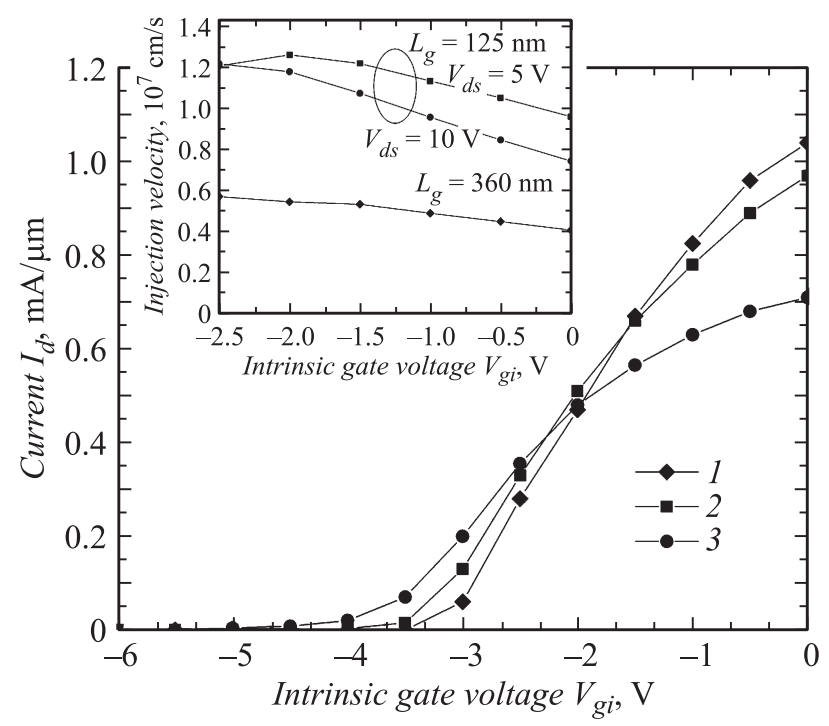

Pис. 2. Зависимость тока стока $I_{d}$ от внутреннего напряжения на затворе $V_{g i}$. 1 - значения для транзистора с длиной затвора $360 \mathrm{~nm}$ при напряжении сток-исток $5 \mathrm{~V}, 2$ и 3 - значения для транзисторов с длиной затвора $125 \mathrm{~nm}$ при напряжении сток-исток 5 и $10 \mathrm{~V}$ соответственно. На вставке показана вычисленная скорость инжекции электронов в подзатворную область в зависимости от $V_{g i}$. Для транзисторов с длиной затвора $360 \mathrm{~nm}$ зависимость показана для напряжения сток-исток $V_{d s}=5 \mathrm{~V}$.

(рис. 2) на значения плотности заряда (рис. 1), мы получили величину скорости инжекции электронов в зависимости от $V_{g i}$ (вставка на рис. 2).

Как видно из вставки к рис. 2, скорость инжекции для изготовленных $\mathrm{AlGaN} / \mathrm{AlN} / \mathrm{GaN}$ HEMT находится в диапазоне от $0.6 \cdot 10^{7}$ до $1.3 \cdot 10^{7} \mathrm{~cm} / \mathrm{s}$. Для транзистора с $L_{g}=125 \mathrm{~nm}$ скорость инжекции электронов примерно в 2 раза больше, чем в случае $L_{g}=360 \mathrm{~nm}$. Это связано с тем, что при уменьшении длины затвора транзистор начинает работать в баллистическом режиме, что приводит к росту $v_{i n j}$. Кроме того, для всех транзисторов наблюдается уменьшение $v_{i n j}$ при приближении напряжения на затворе $V_{g i}$ к нулю, что связано с увеличением рассеяния электронов на фононах из-за разогрева кристаллической решетки током, протекающим в канале транзистора (рис. 2).

Письма в ЖТФ, 2017, том 43, вып. 16 
Рассмотрим теперь зависимости $v_{i n j}$ от $V_{g i}$ для двух напряжений $V_{d s}=5$ и $10 \mathrm{~V}$ между стоком и истоком транзистора с длиной затвора $L_{g}=125 \mathrm{~nm}$ (см. вставку к рис. 2). Видно, что увеличение $V_{d s}$ приводит к более резкому уменьшению $v_{i n j}$ при увеличении $V_{g i}$. Это можно связать с тем, что при большем $V_{d s}$ электроны приобретают бо́льшую энергию и переходят во вторую подзону размерного квантования, волновая функция которой менее локализована в квантовой яме по сравнению с волновой функцией электронов первой подзоны размерного квантования. Это приводит к возрастанию рассеяния электронов на флуктуациях состава барьерного слоя $\mathrm{AlGaN}$ и соответствующему снижению $v_{\text {inj }}$.

Следует отметить, что для транзисторов с $L_{g}=360 \mathrm{~nm}$ зависимость $v_{i n j}$ от $V_{g i}$ более пологая, чем в случае $L_{g}=125 \mathrm{~nm}$. Это можно объяснить следующим образом. При расчетах значения удельной емкости затвора $C_{g i}$ были использованы геометрические размеры затвора (т.е. размеры напыленного металла). При этом в случае „короткого“ затвора $\left(L_{g}=125 \mathrm{~nm}\right)$ нужно дополнительно учитывать влияние короткоканальных эффектов, когда форма подзатворного потенциального барьера зависит от $V_{d s}$ и $V_{g i}$. Следовательно, можно предположить, что различие в скорости спада зависимости $v_{i n j}$ от $V_{g i}$ при одинаковом $V_{d s}=5 \mathrm{~V}$ для $L_{g}=125$ и $360 \mathrm{~nm}$ связано с необходимостью введения эффективной длины затвора для $L_{g}=125 \mathrm{~nm}$.

Таким образом, в работе показано, что уменьшение длины затвора примерно в 3 раза приводит к двукратному возрастанию скорости инжекции электронов в подзатворной области канала AlGaN/AlN/GaN HEMT.

Работа выполнена при финансовой поддержке Минобрнауки РФ (соглашение о предоставлении субсидии № 14.607.21.0124, уникальный идентификатор проекта RFMEFI60715X0124).

\section{Список литературы}

[1] Quay R. Gallium nitride electronics. Berlin-Heidelberg: Springer, 2008. 469 p.

[2] Shinohara K., Regan D.C., Yan Tang R. et al. // IEEE Trans. Electron Devices. 2013. V. 60. N 10. P. 2982-2996.

[3] Lee D.S., Liu Z., Palacios T. // Jpn. J. Appl. Phys. 2014. V. 53. N 10. P. 100212 $(1-10)$.

Письма в ЖТФ, 2017, том 43, вып. 16 
[4] Фёдоров Ю.В., Михайлович С.В. // Нано- и микросистемная техника. 2016. T. 18. № 4. C. 217-226.

[5] Томош К.Н., Павлов А.Ю., Павлов В.Ю., Хабибуллин Р.А. и др. // ФТП. 2016. T. 50. B. 10. C. $1434-1438$.

[6] Галиев Р.Р., Яименев А.Э., Бугаев А.С. и др. // Изв. РАН. Сер. физ. 2016. T. 80. № 4. C. 522-524.

[7] Kim D.-H., del Alamo J.A., Antoniadis D.A., Brar B. // IEEE IEDM Tech. Dig. 2009. P. 861-864.

[8] Михайлович С.В., Фёдоров Ю.В., Бугаев А.С. и др. // Докл. ТУСУР. 2011. T. 2. № 2. Ч. 2. С. 31-35.

[9] Фёдоров Ю.В., Михайлович С.В. // Нано- и микросистемная техника. 2014. № 10. C. $12-17$. 